\title{
Influencing Factors for Chinese Students to Participate in Tutorial Education and the Impact of Participating in Tutorial Education
}

\author{
Chuang Yan \\ College of Marxism \\ Northeast Normal University \\ Changchun, China 130024
}

\begin{abstract}
By investigating the participation of students in tutorial education in four high schools in Changchun and Fushun, the author finds out that individual factors such as family income, education level of father, rank of students, grade of students and type of schools have no significant effects on the participation in tutorial education. To participate in tutorial education has reinforcing effects on the realization of educational equity. At the same time, the study also finds that the proportion of expenditure on tutorial education in household income varies greatly among families with different incomes. It is an "anomalous Engel coefficient". And it would increase the tension of students in middle-income and lowincome families.
\end{abstract}

Keywords-tutorial education; influencing factors; reinforcing effect

\section{INTRODUCTION}

The Chinese government has always attached great importance to the development of education. In recent years, its education has made great strides by gradually increasing its investment in financial education. At the same time, the tutorial education attached to the educational undertaking also takes the opportunity to strengthen itself. This kind of tutorial education, which is mainly manifested in hiring tutors for children or sending their children to cram schools, is beyond the normal education of the school. The family would purchase additional and extra forms of educational services. [1] The "service" attribute of mainstream education (public school education) is an important reason for the prevalence of current tutorial education. However, compared with the "extra" attributes of mainstream education, tutorial education is seen as aggravating the burden on students and hindering the promotion of quality education. Some scholars also regard tutorial education as one of the factors that jeopardize the fairness of education. They think that it enhances the regional differences and the differences between urban and rural areas in education investment from the aspect of the cost-sharing of private education. It would have an adverse effect. [2] In the process of education reform aimed at "reducing burdens" and "fairness", the tutorial education was severely hammered by the Chinese education administration. However, on the one hand, the departments of education continuously hit the tutorial education. On the other hand, these actions can't help prohibit the development of tutorial education. People want to know the reason why the tutorial education enables many members of society to devote themselves. Will its "damaging" effect on educational equity lead to the widespread collapse of education fairness due to the involvement of many people? In order to find out the answers to these questions, the author conducts social survey on students who participate in remedial education in Changchun and Fushun. The survey focuses on two factors that affect Chinese students' participation in tutorial education and the impact of participating in tutorial education.

\section{THE SURVEY DESIGN}

The high school has been influenced by the "baton" of college entrance examination. It has been the disaster area of tutorial education. Therefore, the author chooses one of the key and non-key high schools in Changchun and Fushun as the sampling unit. And the author uses the combination of stratified sampling and cluster sampling to randomly select some of the current students to conduct the questionnaire survey. 698 questionnaires were issued. 677 were effectively recovered. And the recovery rate of effective questionnaire was $96.7 \%$

In order to effectively analyze the factors that may influence the participation in tutorial education, the author would make the regression analysis of dichotomous variable. And he uses the method of binary logistic regression to achieve the above-mentioned goal. Specific mode of operation is shown as the following. The author would construct a dichotomous variable to describe the reality of individual students participating in tutorial education. For example, the surveyed students choose the answer of "not participating in tutorial education during the high school education". And the assignment of this variable is 0 . If the students choose the answer of "participating in tutorial education in high school", the assignment of this variable is 1. Based on the existing research literature of China National Knowledge Infrastructure (CNKI), the author finally chose five variables such as family income, father's education, grade rankings of students, grade of students and the type of 
school. And the author would take five variables as the explanatory variable of logistic regressive model. Based on the above dichotomous and explanatory variables, the research design can be modeled as $\operatorname{Ln}[\mathrm{Ps} /(1-\mathrm{Ps})]=\mathrm{f}(\mathrm{i}, \mathrm{d}, \mathrm{r}$, $\mathrm{g}$, t). Among them, Ps refers to the probabilities of participating in the tutorial education of the investigated students. (1-Ps) refers to the probability of not participating in the tutorial education. And the dependent variable in the model refers to the log odds of participating in the tutorial education of the investigated students. That is to say, Ln [Ps / (1-Ps)] is a conversion form of the probability of occurrence (P). In addition, the variable "i" refers to the annual family income. 30,000 yuan and below is assigned to 1.30001 yuan to 60000 yuan is assigned to 2. 60001 yuan to 120000 yuan is assigned to 3. And 120001 yuan and above is assigned to 4 . The variable $d$ indicates the father's education. To have no education experience is assigned to 1 . To have primary school education is assigned to 2 . To have secondary school education is assigned to 3 . To have university education is assigned to 4 . To have master education or above is assigned to 5 . The variable $r$ refers to the grade rankings of students. The grade ranking of 401 and later is assigned to 1 . The grade ranking of 201-400 is assigned to 2 . The grade ranking of $0-200$ is assigned to 3 . The variable $\mathrm{g}$ refers to the grade of the student. And first-year senior high school is assigned to 1 . The junior high school is assigned to 2 . The third-year senior high school is assigned to 3 . The variable $t$ refers to the type of school. The regular senior secondary school is assigned to 0 . The key senior high school is assigned to 1 .

\section{THE ANALYSIS OF RESULTS}

\section{A. The Basic Situation of Participating in Tutorial Education}

Among the surveyed high school students, a total of 583 students chose the answer of "participating in tutorial education in high school". And it accounts for $86.1 \%$ of the surveyed students. Only 94 students chose the answer of "not participating in tutorial education in high school". It accounts for $13.9 \%$ of the total. After the comparison, we can see that high school students who participate in tutorial education are 9 times of their peers who don't participate in tutorial education. According to this survey, we can see that the large number of people participate in the tutorial education. The scale of the tutorial education is huge. The situation of "universal participation in tutorial education" quietly emerged.

\section{B. The Situation of Tutorial Education Expenses}

Tutorial education is a form of "additional education services bought by families". And to pay certain expenses has become necessary prerequisite for obtaining the opportunities to have tutorial education. The survey finds that the tutorial education costs a lot. And the average expenditure of participating in tutorial education is as high as $6,437.3$ yuan. In addition, the author also finds that the proportion of annual education expenditure in annual household income is negatively correlated with the annual income of the family. That is to say, with the decrease of the annual income of the family, it increases the proportion of the annual expenditure on education. What is noteworthy, some students from low-income families are more likely to feel pressure of paying for tutorial education than their classmates.

First, the relationship between tutoring expenses and household income shows an "anomalous Engel's coefficient". In general, a higher Engel's coefficient indicates that one family or country has lower or poorer incomes. A lower Engel's coefficient indicates that one family or country has higher incomes. According to the survey, after distinguishing the types of family income surveyed, the percentage of annual expenditure on tutorial education in the annual household income was negatively correlated with the annual household income. The changing law is similar to that of the Engel's coefficient. For example, among those samples, the percentage of annual expenditure on tutorial education in the annual household income is above $40 \% .37 .2 \%$ of them earn less than 30,000 yuan. $31.0 \%$ of them have 30001 yuan to 60,000 yuan. And only $8.2 \%$ of them have 60001 yuan to 120,000 yuan. $3.2 \%$ of them have 120,000 yuan. However, after in-depth thinking, we can find out that the expenditures on tutorial education take the share originally used for purchasing food. As a result, in a family with students participating in tutorial education, the less a family earns, the smaller the proportion of family income spent on food purchases. As household incomes increase, the proportion of household income spent on food purchases rises. This is very different from the connotation of the Engel's coefficient. In other words, the "decline in the proportion of household income spent on food purchases" doesn't mean that a household is rich in income. The author calls this phenomenon "abnormal Engel coefficient" in tutorial education.

Second, to participate in tutorial education increases the mental stress of students in some family. After entering secondary school, individual students would have formed more mature judgments. They would have more profound understanding of their families' economic efforts. According to the survey results, the response of the students in some low-income families to the above content would be obvious. For example, among the students who feel the pressures of paying for tutorial education, $87.50 \%$ of families earn less than 30,000 yuan each year. $61.89 \%$ of them have family incomes from 31,001 to 60,000 yuan. The family incomes from 61,001 to 120,000 yuan and over 120,000 yuan only accounted for $19.31 \%$ and $6.86 \%$ respectively. It can be seen that in the face of tutorial education fees, the author should take the annual family income as the reference standard. The students in low-income families undertake greater mental pressure than that of those in relatively wealthy families.

\section{The Influencing Factors of Participating in Tutorial Education}

According to the survey results, individual differences have no significant effects on participating in tutorial education. The selected variables such as family income, father's education level, grade ranking of students, grade of the students and the type of school were substituted into 
logistic regression model. And the way is enter. The regression probability is 0.05 . After using spss 17.0 software, the author obtains the following logistic regression analysis of the influencing factors of participating in tutorial education.

TABLE I. LOGISTIC REGRESSION ANALYSIS ON INFLUENCING FACTORS OF PARTICIPATING IN TUTORIAL EDUCATION

\begin{tabular}{|l|l|c|c|c|c|c|c|}
\hline & B & S.E, & Wals & df & Sig. & Exp (B) \\
\hline Step 1a & household income & -.077 & .139 & .307 & 1 & .580 & .926 \\
\cline { 2 - 8 } & father's educational level & -.064 & .119 & .290 & 1 & .590 & .938 \\
\hline grade ranking & .003 & .149 & .000 & 1 & .986 & 1.003 \\
\hline grade of students & -.230 & .142 & 2.619 & 1 & .106 & .794 \\
\hline type of school & -.298 & .226 & 1.730 & 1 & .188 & .742 \\
\hline constant (quantity) & 2.824 & .566 & 24.904 & 1 & .000 & 16.845 \\
\hline
\end{tabular}

${ }^{\text {a. }}$ The input variables would be set in step 1 . It includes family income, educational level of father, grade rankings, current grade and the type of school

From "Table I", the author must control other variables. The selected research variables have entered the regression equation. They have no statistical significance on the impact of participating in the tutorial education for the students. The Sig values of the two variables of family income and father's education were 0.58 and 0.59 respectively. They are much higher than the regression probability of 0.05 . This indicated that there was no significant relationship between the two groups and the sign of the regression coefficient of the two variables. It shows that due to low income and father's low education level, the students are more motivated to participate in tutorial education. The rankings of student are the only variables with sign of positive regression coefficient. It indicates that there is a positive correlation between the variables and students' participation in tutorial education. Although the Sig value also reflects that this variable does not have significant influence on participating in tutorial education for the interviewed students. According to the sign of negative regression coefficient of the two variables such as the grade of the students and the type of the school, it shows that students in the lower grades and non-key schools are more active in participating in the tutorial education than the students who are in senior and key schools. However, these two variables have no significant influences on participating in tutorial education.

The ranking of students have no significant impact on whether participating in the tutorial education. And it indicates that the tutorial education has similar appeal to students with different achievements. In the author's opinion, the enthusiasm of junior students to participate in tutorial education is better than that of senior students. We can know that the senior students in the current educational environment have too long time to learn in school, which in turn leads to lack of autonomy in participating in tutorial education. Comparatively, junior students have much time. And they are more likely to attend tutorial education. There was no significant correlation among the three variables of family income, education level of father and the type of school attended by the surveyed students. It indicates that the participation in tutorial education was not significantly impacted by their individual preconditioning education.
According to the negative regression coefficient symbols, the surveyed students who may be in the disadvantaged position of the three variables are more likely to participate in tutorial education. In the author's opinion, there was no significant correlation among family income, education level of father, the type of school and the attendance of remedial education. To some extent, the students would break the tutorial education limited by the accumulation of pre-emptive conditions. And it would have reinforcing effect on the goal of educational fairness.

Some scholars have confirmed that there is a very close relationship between the grade of the students and the individual pre-emptive factors of the students. By turning the resources superiority into the superiority of the children's education, it would lead to the educational inequality. And then, it would lead to the reproduction of social stratification or the transfer of social status from generation to generation. [3] The close relationship between this type of school and its individual preconditions is also reflected in the survey data obtained by the author.

TABLE II. LOGISTIC REGRESSION ANALYSIS ON SCHOOL TYPE, FAMILY INCOME AND FATHER'S EDUCATIONAL LEVEL

\begin{tabular}{|l|l|c|c|c|c|c|l|}
\hline & B & S.E, & Wals & df & Sig. & Exp (B) \\
\hline Step 1a & household income & .240 & .097 & 6.162 & 1 & .013 & 1.271 \\
\cline { 2 - 8 } & father's educational level & .204 & .085 & 5.820 & 1 & .016 & 1.226 \\
\cline { 2 - 8 } & constant (quantity) & -1.624 & .333 & 23.735 & 1 & .000 & .197 \\
\hline
\end{tabular}

b. The author would input the variables of family income and father's educational level in step 1

In "Table II", the type of school is dependent variable. And the family income and father's educational level are independent variable. Then, the author makes the logistic regression analysis. The author set the way is "enter". And the regression probability is 0.05 . There is an extremely significant and positive relationship between the two variables and the school type. We can say that the higher the family income and the higher the education level of the father is, the possibility the student will attend key high schools. According to the German scholar Weber's elaboration on his social stratification of "Trinity" theory, the economic conditions characterized by household income and the social reputation characterized by education are the important criteria for social stratification. [4] According to these criteria, the parents who are already in the upper and middle class of society have significantly influenced the selection of their children's schools. Due to the preconditions accumulated by the parents, it would have some differences. There are specific differences such as the objective teaching staff, the teaching level and the proportion of entering a higher school. A series of specific differences will become an important basis for children to acquire social stratification position again. In other words, mainstream school education affected by the stratification of society has experienced some degree of inequality. As international development continues, inequalities in mainstream school education will solidify existing social stratification systems. And it would have impacts on social equality seriously. 


\section{DISCUSSION}

\section{A. Tutorial Education Shows the Situation of "Full Participation"}

Tutorial education has spread in the current society, showing a situation of "universal participation". Students participating in the tutorial education accounted for the absolute advantage of the number of people in the group. Students of different grades, schools, rankings, family income and parental education participate in tutorial education. And it doesn't differ by individual differences. According to this, the tutorial education almost covered all of the respondents. There has been an upsurge of tutoring education, which is almost "universal participation". It also reveals the reason for the formation of "tutorial education fever". It has exceeded the micro-individual level of social members. Any treatment measures of tutorial education that attempts to change the attitudes of individual students and parents will have no results.

\section{B. Tutorial Education Has Changed the Living Consumption Structure of Low and Middle-income Families and Aggravated Role Tension of Students}

Tutorial education doesn't carry the attributes of social stratification based on individual preconditions. And it doesn't like the mainstream school education. It objectively reduces the threshold for tutorial education and facilitates individual members of society to obtain tutorial education resources. To some extent, it has reinforcing effect on the fairness of social education. However, to participate in tutorial education must pay the fees. And the families participating in tutorial education inevitably have some economic burden. Especially, for low-income families, the burden is greater. It is consist with the opinions of some scholars. They think that tutorial education has bad effects on the objective of fairness.

According to the survey, the proportion of tuition spending in household income shows that among low and middle income families with annual income below 60,000 yuan, their expenditures on tutorial education account for almost one fifth of the total family income. And their expenditures become an important part of household consumption expenditure. This shows that education is highly valued by members of society. They don't care the investment. And it became an important social integration media. On the other hand, the consumption structure of lowincome families in daily life is not reasonable. With such consumption structure of household daily living, the cost of tutoring education is a large-scale consumption expenditure project for low and middle income families. It will inevitably reduce the proportion of expenditure needed for basic necessities such as food expenditures. It would lead to the phenomenon of "abnormal Engel coefficient". And it violates traditional social norms and the general law of human development in "Engel's Coefficient theory" and "Maslow's hierarchy of needs theory". The author defines it as a kind of "anomie behavior" that violates the basic human needs such as survival needs. And the actors will also bear the additional tension due to the "anomie behaviors".
According to the explanation of sociological theory, a variety of roles (norms) puts forward the requests for the bearer at the same time. The bearer can't adapt to the social phenomenon. It could be called role tension. [4] Specifically, compared with their peers, students in low and mediumincome families should complete the learning tasks expected by the society. In addition to their normal role of student, they will also face the extraordinary expectations of participating in tutorial education. They should play the "success" role of fulfilling the family's hopes. It is beyond the normal role of student. The students would have no choice in the process of "hoping their children can become dragon and phoenix". Of course, it greatly increases the mental burden of these students. In recent years, there has been an increase in student suicide incidents. The relevant departments must pay enough attention to it.

\section{Tutorial Education Has Reinforcing Effect on the Realization of Educational Fairness}

Education is the driving force of social mobility. To have access to educational opportunities is the center of social stratification research. [5] In the face of China's actual national conditions, it is impossible to distribute such an important and limited educational resource in equal shares. They can only be distributed on the principle of equal opportunity. That is to say, the conditions should be public. If the students meet these conditions, they should get the opportunities. The principle of equal opportunity is based on certain additional conditions. And then, they would allocate the opportunities. This principle presupposes the reasonableness of the conditional disparity of members in the society. This requires that when implementing the principle of equal opportunity, we should abandon the individual preconditions. Based on the conditions of acquisitiveness acquired by members of the society as the basis for allocating opportunities, efforts should be made to narrow the gap between the actual conditions of members and maximize social equality. [4] However, the contents of the survey have confirmed that attending key high schools and obtaining excellent educational resources are highly correlated with the preconditions given by individual students, such as family income and father's education. These preconditions inevitably would lead to the educational inequality. It is the departure from the principle of equal opportunity. And it is also the detriment to the education fairness.

Different from the acquisition of educational resources of the school type, to participate in tutorial education is not limited by the individual's prior condition. To some extent, it would ease the educational unfairness that the school type is marked with "parent accumulation". According to the survey, many variables such as school type, grade rankings of students, family annual income and father's education were not significantly related to whether students participating in tutorial education. In other words, high school students could not be influenced by individual conditions. The students virtually choose whether or not to participate in tutorial education. This is an important precondition for the emergence of "full tutorial education". To study in different 
types of school may widen their individual education gaps. To participate in tutorial education may effectively bridge the educational gap between such individuals. The students with different preconditions would participate in the college entrance examination, which is typical system design under the principle of equal opportunity. It will not be unfair due to the large gap. In this sense, tutorial education has reinforcing effect on the realization of education fairness.

According to the survey, students living in disadvantaged families with low household income, low education of father and schools are more motivated to participate in tutorial education. They depend on tutorial education. They also prefer to use tutorial education to bridge the gap between peer groups. And then, these students would participate in college entrance examination and other education test, which is set up based on the principle of equal opportunity. The students would have high-level educational resources and the opportunities of social mobility. In this sense, the author believes that these inferior student groups' passion for participating in tutorial education is essentially a strategy of "self-help for disadvantaged groups based on rational choice". It can provide this kind of communitarian with the equality of education.

\section{CONCLUSION}

The author originally tries to explore the influencing factors of participating in tutorial education. According to the results, it did not receive any statistically significant differences in the selected elements. And it can be said that it is "failure to investigate". However, this "failure" just shows that many variables such as the type of school, ranks of students, family annual income and father's education have no significant effect on participating in tutorial education behavior. Especially, family income and father's education which are highly related to individual pre-emptive conditions have same performance. The author's investigation of the influencing factors of participating in tutorial education directly became the conclusion of the influence of participating in tutorial education. That is to say, the interviewed students could choose whether or not to participate in tutorial education equally. And tutorial education had an important reinforcing effect on the realization of educational equity. Of course, the survey also shows that the cost of tutorial education is particularly burdensome for low and middle-income families. It is consistent with some scholars' belief that tutorial education has "damaging" effect on the goal of educational equity. Also, the living expenses of these families would exacerbate the degree of tension among students.

\section{REFERENCES}

[1] Xue Haiping, Ding Xiaohao. Study on tutorial education of Chinese urban student [J]. Educational Research, 2009 (1): 39-40.

[2] Lei Wanpeng. The expenditure of tutorial education of senior high school student: influencing factors and policy implications [J]. Education and Economy, 2005 (1): 42.

[3] Chen Youhua, Fang Changchun. Social stratification and the diversion of education - An empirical study on the fairness of institutional arrangements such as "planning for admission to schools" in compulsory education [J]. Jiangsu Social Sciences, 2007 (1): $232-234$.

[4] Zheng Hangsheng editor. Introduction to Sociology (revised version) [M]. Beijing: Renmin University of China Press, 1998: 297,156, 306307.

[5] Li Chunling. Social and political changes and the inequality of educational opportunities - the impact of family background and institutional factors on education (1940-2001) [J]. Social Sciences in China, 2003 (3): 86. 